\title{
KARAKTERISASI RESERVOIR HIDROKARBON MENGGUNAKAN ATRIBUT SWEETNESS DAN INVERSI IMPEDANSI AKUSTIK DI PERAIRAN UTARA BALI
}

\section{CHARACTERIZATION OF HYDROCARBON RESERVOIR USING SWEETNESS ATTRIBUTE AND ACOUSTIC IMPEDANCE INVERSION IN NORTH BALI WATERS}

\author{
Aulia Ranggi Pamalik ${ }^{1}$, Henry M. Manik ${ }^{2 *}, \&$ Susilohadi $^{3}$ \\ ${ }^{1}$ Program Studi Teknologi Kelautan, Sekolah Pascasarjana, IPB University, Bogor, 16680, Indonesia \\ ${ }^{2}$ Departemen Ilmu dan Teknologi Kelautan, FPIK-IPB University, Bogor, 16680, Indonesia \\ ${ }^{3}$ Pusat Penelitian dan Pengembangan Geologi Kelautan, Bandung, 40174, Indonesia \\ *E-mail: henrymanik@apps.ipb.ac.id
}

\begin{abstract}
Reservoir is an object that be focus at exploration stage of the oil and gas industry. The process of identifying and depicting reservoir characters both qualitatively and quantitatively is carried out using well and seismic data because these two data are complementary. The aim of this study is to identify and analyze the character of hydrocarbon reservoir in North Bali Waters using sweetness attribute method and model-based acoustic impedance inversion method. This study uses four $2 \mathrm{D}$ post-stack time migration seismic and a well (BLJ-1) data. The sweetness attribute method is carried out by extracting basic information derivatives from seismic data (amplitude and frequency), while the model-based acoustic impedance inversion method is carried out by integrating seismic and well data in order to obtain the lateral distribution of acoustic impedance values. The results showed that sweetness attribute can identify the hydrocarbon reservoir zone from sweet spots anomaly at time window 750-850 ms. The main reservoir zone is composed by carbonate rocks (limestone) aged Late Pliocene and located at 680-740 m depth. Model-based inversion method is able to provide high correlation values and low inversion errors, so it can determines the rock layers that predicted with gas-contain. The use of sweetness attribute and model-based inversion method can identify and describe reservoir characters well.
\end{abstract}

Keywords: carbonate, hydrocarbon, reservoir characterization, seismic attribute, seismic inversion

\begin{abstract}
ABSTRAK
Reservoir adalah salah satu objek yang menjadi fokus pada tahap eksplorasi dalam industri minyak dan gas. Proses identifikasi dan penggambaran karakter reservoir baik secara kualitatif maupun kuantitatif dilakukan menggunakan data sumur dan data seismik karena kedua data tersebut saling melengkapi. Tujuan penelitian ini adalah mengidentifikasi dan menganalisis karakter reservoir hidrokarbon di Perairan Utara Bali menggunakan metode atribut sweetness dan metode inversi impedansi akustik berbasis model. Penelitian ini menggunakan empat buah lintasan seismik laut 2D post-stack time migration dan sebuah data sumur (BLJ-1). Metode atribut sweetness dilakukan dengan menurunkan informasi data seismik berupa amplitudo dan frekuensi, sedangkan metode inversi impedansi akustik berbasis model dilakukan dengan mengin-tegrasikan data seismik dan data sumur agar diperoleh sebaran nilai impedansi akustik secara lateral. Hasil penelitian menunjukkan bahwa atribut sweetness dapat mengenali zona reservoir hidrokarbon dari anomali sweet spots pada rentang waktu 750-850 ms. Zona reservoir utamanya tersusun atas batuan karbonat berupa batu gamping (limestone) yang berumur Late Pliocene dan terletak pada kedalaman 680-740 m. Metode inversi berbasis model mampu memberikan nilai korelasi yang tinggi dan galat inversi yang rendah sehingga dapat mendeterminasi lapisan batuan yang diprediksi mengandung gas. Penggunaan atribut sweetness dan inversi berbasis model, dapat mengidentifikasi dan mampu menggambarkan karakter reservoir dengan baik.
\end{abstract}

Kata kunci: atribut seismik, hidrokarbon, inversi seismik, karakterisasi reservoir, karbonat 


\section{PENDAHULUAN}

Pada kegiatan eksplorasi sumber daya minyak dan gas (migas), salah satu target utama yang menjadi fokus perhatian adalah reservoir (Febridon et al., 2018). Reservoir merupakan batuan bawah permukaan yang berpori dan permeabel, serta memiliki kemampuan untuk menyimpan dan mengalirkan fluida seperti hidrokarbon. Umumnya, batuan reservoir dapat tersusun atas batu pasir, konglomerat, batu lanau, dan batu gamping (Sukandarrumidi, 2017). Keberadaan reservoir dapat diidentifikasi menggunakan suatu metode yang mampu menggambarkan kondisi bawah permukaan dengan baik. Metode seismik merupakan salah satu metode yang tepat dan kerap kali digunakan untuk menggambarkan kondisi bawah permukaan. Data hasil metode seismik ini dapat langsung diinterpretasikan sebagai citra penampang seismik atau dapat diproses lebih lanjut untuk proses karakterisasi reservoir hidrokarbon.

Karakterisasi reservoir menurut Sukmono (2002) merupakan suatu proses untuk menggambarkan karakter reservoir baik secara kualitatif maupun kuantitatif dengan menggunakan seluruh data yang ada. Beberapa teknik atau cara yang dapat digunakan untuk mengkarakterisasi reservoir adalah dengan menggunakan atribut seismik dan inversi seismik (Chen \& Sidney, 1997; Helland-Hansen et al., 1997). Atribut seismik merupakan derivatif atau turunan dari informasi dasar data seismik yang berupa waktu, amplitudo, frekuensi, dan atenuasi (Brown, 2001). Turunan dari informasi dasar tersebut, akan memiliki respons tertentu sehingga dapat mengindikasikan keberadaan zona reservoir hidrokarbon. Selain menggunakan atribut seismik yang dihasilkan dengan menurunkan informasi dari data seismik, agar lebih akurat proses karakterisasi reservoir juga dilakukan dengan mengintegrasikan data seismik dan data pencatatan sumur (well logging) melalui inversi seismik. Inversi seismik adalah suatu upaya rekonstruksi sifat fisis bumi berdasarkan informasi dari data seismik. Salah satu produk yang dihasilkan dari inversi seismik adalah impedansi akustik. Impedansi akustik dapat diartikan sebagai kemampuan batuan dalam melewatkan gelombang seismik. Komponen tersebut sangat dipengaruhi oleh velositas gelombang dan densitas batuan sebagai respons dari perbedaan litologi dan kandungan fluida (Erryansyah et al., 2019; Simanjuntak et al., 2014).

Perairan Utara Bali merupakan wilayah perairan yang masih menjadi bagian dari Cekungan Jawa Timur. Studi mengenai geokimia hidrokarbon yang telah dilakukan sebelumnya (Phillips et al., 1991; Satyana \& Purwaningsih, 2003), menyatakan bahwa wilayah tersebut memiliki umur paparan batuan yang tua sehingga dapat mengindikasikan dan memungkinkan terbentuknya hidrokarbon. Hal ini terbukti dengan penemuan hidrokarbon berupa gas pada wilayah perairan tersebut sejak 3 dekade yang lalu (Saputra et al., 2014). Berdasarkan pemaparan di atas, gabungan metode atribut seismik dan inversi seismik digunakan agar dapat memberikan informasi yang lebih lengkap pada tahap karakterisasi reservoir hidrokarbon. Tujuan penelitian ini adalah mengidentifikasi dan menganalisis karakter reservoir hidrokarbon di Perairan Utara Bali menggunakan metode atribut seismik, yaitu atribut sweetness dan metode inversi impedansi akustik berbasis model.

\section{METODE PENELITIAN}

\subsection{Data Seismik}

Penelitian ini menggunakan data seismik yang terletak di Perairan Utara Bali. Data seismik tersebut merupakan data seismik 2D yang telah mengalami pemrosesan akhir post-stack time migration dan terdiri atas 4 buah lintasan, yaitu SL1, SL2, K1, dan K2. Lintasan SL1 dan SL2 adalah data seismik yang diakuisisi pada tahun 2017 oleh tim survei Pusat Penelitian dan Pengembangan Geologi Kelautan (PPPGL) 
menggunakan kapal riset Geomarin III, sedangkan lintasan K1 dan K2 adalah data sekunder dari Pusat Data dan Teknologi Informasi (Pusdatin) Kementerian ESDM. Lokasi penelitian selanjutnya dapat dilihat pada Figure 1.

Berdasarkan lokasi penelitian, tiga lintasan seismik berorientasi pada arah utara-selatan dan satu lintasan seismik berorientasi pada arah barat-timur. Masingmasing lintasan seismik memiliki jumlah jejak seismik atau seismic trace sebesar 6047 (SL1), 5677 (SL2), 1440 (K1), dan 2191 (K2). Lintasan seismik K1 memiliki jarak yang paling dekat terhadap sumur BLJ1 dibandingkan lintasan lainnya, yakni seki$\operatorname{tar} 18 \mathrm{~m}$ dan lintasan inilah yang akan digunakan untuk analisis atribut sweetness dan inversi impedansi akustik.

\subsection{Data Sumur}

Sumur BLJ-1 memiliki status sebagai sumur eksplorasi, yaitu sumur yang dibor untuk membuktikan keterdapatan hidrokarbon (minyak dan gas) pada lokasi baru. Sumur ini dibor pada kedalaman $308 \mathrm{ft}$ atau sekitar 93,88 m di bawah permukaan laut dengan total kedalaman sumur sebesar 7444 $\mathrm{ft}(2268,93 \mathrm{~m})$. Data sumur pada penelitian ini memiliki data utama berupa data pengukuran, seperti checkshot, log gamma ray (GR), log resistivity (MSFL, ILD, dan SFLU), $\log P$-wave, log neutron porosity (NPHI), dan log densitas (RHOB). Data lainnya seperti data marker umur batuan dan data drill stem test (DST) juga digunakan untuk menunjang proses karakterisasi reservoir.

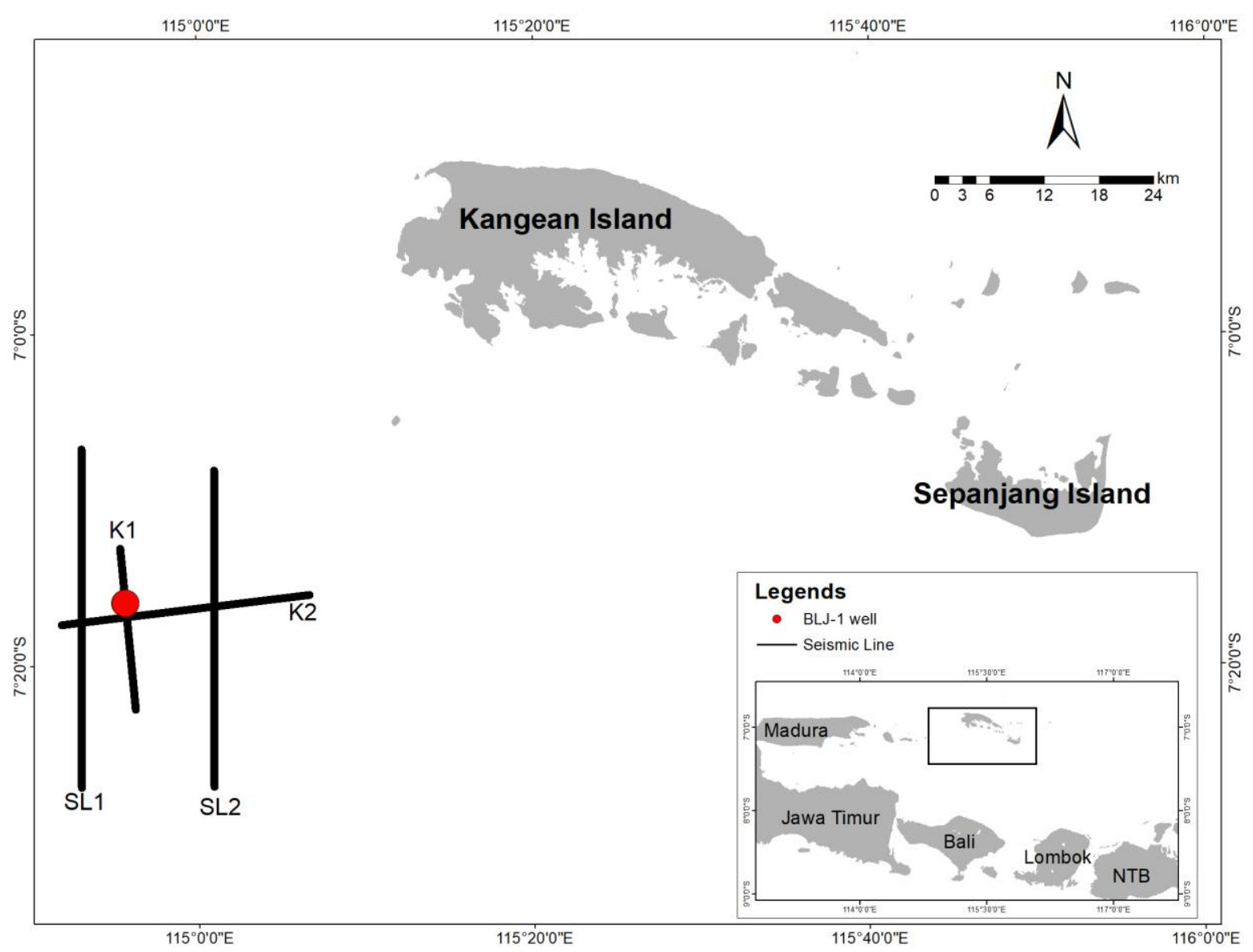

Figure 1. Map of North Bali Waters showing the study area with seismic lines and well location. 


\subsection{Metode Atribut Sweetness}

Metode atribut sweetness pada penelitian ini digunakan untuk mengidentifikasi "sweet spots" sebagai indikasi keberadaan hidrokarbon. Atribut sweetness adalah implementasi dari dua atribut gabungan, yaitu atribut envelope dan atribut instantaneous frequency (James et al., 2016). Selanjutnya, Koson et al. (2014) menuliskan perhitungan atribut tersebut dalam persamaan :

$s(t)=\frac{a(t)}{\sqrt{f_{a}(t)}}$

Keterangan: $s(t)$ adalah sweetness, $a(t)$ adalah trace envelope atau amplitudo sesaat, dan $f_{a}(t)$ adalah frekuensi sesaat (instantaneous frequency).

\subsection{Metode Inversi Berbasis Model}

Metode inversi seismik secara umum dapat diartikan sebagai kebalikan dari metode perekaman data seismik. Metode perekaman data seismik mengaplikasikan teknik forward modelling yang pada dasarnya adalah proses konvolusi antara komponen wavelet dan reflektivitas bumi. Langkah pada proses inversi seismik dan proses perekaman data seismik dapat dilihat pada Figure 2.

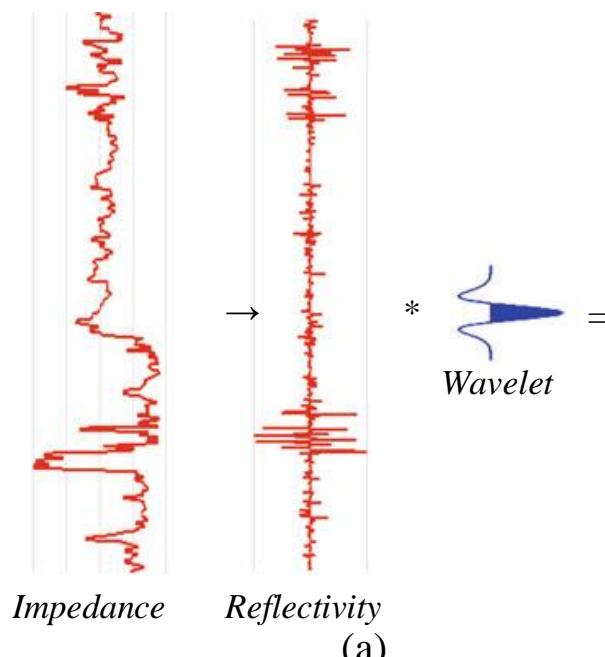

(a)
Komponen reflektivitas pada perekaman data seismik, dianggap sebagai respons dari wavelet seismik terhadap perubahan impedansi akustik pada lapisan bumi. Hubungan antara komponen reflektivitas dan impedansi dapat dituliskan secara matematis dalam persamaan:

$r_{i}=\frac{v_{i+1} \rho_{i+1}-v_{i} \rho_{i}}{v_{i+1} \rho_{i+1}+v_{i} \rho_{i}}=\frac{z_{i+1}-z_{i}}{z_{i+1}+z_{i}}$

Persamaan 2 dapat diinversikan secara langsung menjadi:

$Z_{i+1}=Z_{i}\left[\frac{1+r_{i}}{1-r_{i}}\right]$

Keterangan: $r$ adalah koefisien refleksi, $\rho$ adalah densitas, $v$ adalah velositas gelombang kompresi, $Z$ adalah impedansi akustik, dan $i$ adalah banyaknya lapisan.

Pada penelitian ini, metode inversi seismik dilakukan dengan membangun model geologi awal dan membandingkan antara model geologi tersebut dengan data seismik. Hasil dari perbandingan antara data sebenarnya dengan data hasil model, akan memperbarui model secara iterasi agar lebih sesuai dengan data seismik. Proses iterasi tersebut menyebabkan impedansi akustik awal yang dibangun berdasarkan model geologi akan

Figure 2. The steps of (a) seismic data recording in the form of forward modelling and $(b)$ seismic inversion (Nanda, 2016). 


\section{Model-driven inversion technique}

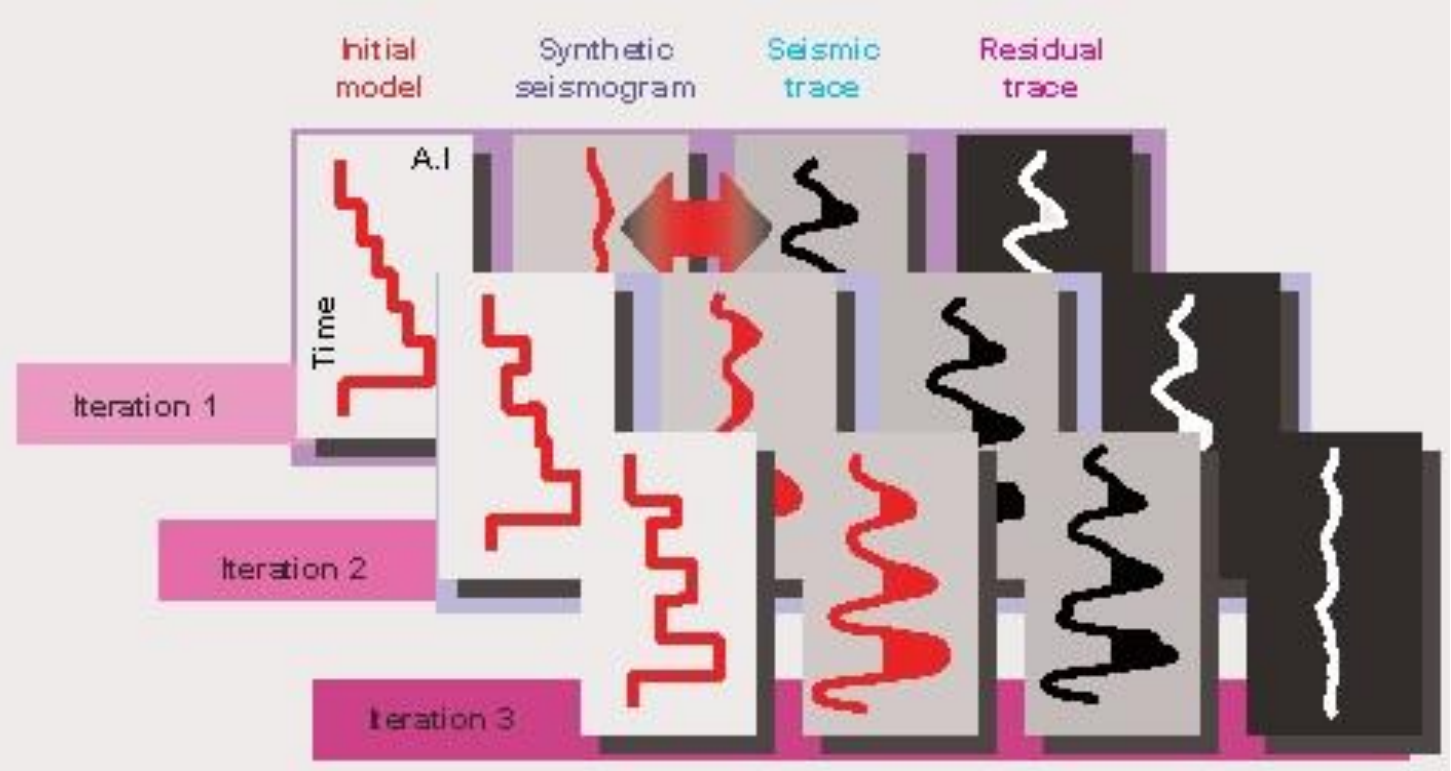

Figure 3. The iteration process in model based inversion (Veeken \& Da Silva, 2004).

berubah mendekati model impedansi akustik dari data seismik seperti pada Figure 3.

Model yang digunakan pada inversi seismik berbasis model ini dibangun berdasarkan metode GLI (Generalized Linear Inversion). Metode GLI adalah suatu metode yang dapat diterapkan di hampir seluruh set virtual dari pengukuran geofisika untuk mendeterminasi situasi geologi yang menghasilkan hasil ini. Secara matematis, proses iterasi yang dibangun pada metode inversi berbasis model dapat ditulis dengan persamaan (Russell, 1988):

$F(M)=F\left(M_{0}\right)+\frac{\partial F\left(M_{0}\right)}{\partial M} \Delta M$

Keterangan: $M_{0}$ adalah model inisial, $M$ adalah model bumi sebenarnya, $\Delta M$ adalah perubahan pada parameter model, $F(M)$ adalah pengamatan, $F\left(M_{0}\right)$ adalah nilai perhitungan dari model inisial, dan $\frac{\partial F\left(M_{0}\right)}{\partial M}$ adalah perubahan pada nilai perhitungan.

\subsection{Pemrosesan Data}

Data seismik dan data sumur diproses menggunakan peralatan pemrosesan data, yaitu unit komputer yang terintegrasi dengan perangkat lunak Seisee, Petrel, Hampson-Russell (HRS), ArcGIS, dan Microsoft Excel. Pemrosesan data dibagi menjadi 2, yaitu pemrosesan inversi seismik (inversi impedansi akustik berbasis model) dan atribut seismik (sweetness). Pemrosesan atribut sweetness dimulai dengan mengatur sistem koordinat atau proyeksi geografis data seismik pada perangkat lunak Petrel sebelum data seismik dimuat. Setelah data seismik termuat, metode atribut sweetness dapat diterapkan melalui package berupa volume attributes.

Pemrosesan inversi seismik dilakukan menggunakan perangkat lunak Hampson-Russell dengan terlebih dahulu melakukan pengkondisian (conditioning) data, membuat log turunan (log impedansi akustik), dan analisis data sumur (data log). Pengkondisian data dilakukan dengan memuat (loading) data sumur dan data seismik, serta membuat basis data (database) sumur yang berisi data log, data marker umur batuan, dan informasi mengenai geometri sumur. Proses pembuatan log turunan (log impedansi akustik) dilakukan dengan me- 
ngalikan log densitas dengan log $P$-wave. Selanjutnya, dilakukan analisis terhadap data sumur untuk menentukan zona target yang diduga sebagai daerah reservoir hidrokarbon.

Setelah zona target teridentifikasi, data sumur dan seismik kemudian diikat (well-to-seismic tie) untuk menyamakan domain pada kedua data. Proses ini diawali dengan mengetahui koefisien refleksi dari data $\log P$-wave yang sudah terkoreksi data checkshot dan log densitas. Koefisien refleksi dikonvolusikan dengan wavelet untuk menghasilkan seismogram sintetik. Seismogram sintetik yang telah dihasilkan kemudian dicocokan dengan trace seismik khususnya di daerah sumur. Tingkat kecocokan antara trace seismik dan seismogram sintetik dilihat berdasarkan nilai korelasi dan juga kesesuaian secara geologi di area target. Hasil well-to-seismic tie dapat digunakan untuk mengidentifikasi lokasi zona target pada data seismik yang selanjutnya diperlukan untuk tahap penelusuran horizon.

Penelusuran horizon dilakukan dengan menentukan garis secara horizontal pada suatu kemenerusan lapisan penampang seismik. Garis horizon tersebut dibuat dengan mengacu pada struktur geologi yang terdapat pada data marker umur batuan. Garis tersebut digunakan sebagai batas area kedalaman yang diduga kedalaman target, serta sebagai kontrol secara lateral dalam pembuatan model inisial bumi. Model inisial bumi dibuat menggunakan data seismik dan data log impedansi akustik. Model ini digunakan sebagai model awal dan sebagai kontrol pada proses inversi seismik. Selanjutnya, dilakukan analisis prainversi dengan membandingkan model inisial bumi dan model inversi. Analisis tersebut dilakukan secara kuantitatif berdasarkan kesesuaian terhadap struktur geologi, nilai korelasi, dan nilai eror dari perbandingan kedua model. Setelah mendapatkan parameter yang sesuai, proses selanjutnya adalah proses inversi impedansi akustik.

\section{HASIL DAN PEMBAHASAN}

\subsection{Analisis Atribut Sweetness}

Data seismik memiliki informasi dasar berupa waktu, amplitudo, frekuensi, dan atenuasi yang dapat diturunkan atau diubah menjadi bentuk atribut seismik. Atribut sweetness merupakan salah satu atribut seismik hasil turunan dari informasi data seismik berupa amplitudo dan frekuensi. Penerapan atribut sweetness pada data seismik, dapat mengidentifikasi anomali berupa "sweet spots" sebagai indikasi adanya hidrokarbon (Zulivandama et al., 2018). Anomali tersebut harus disesuaikan terlebih dahulu dengan data sumur agar informasi yang diperoleh saling melengkapi. Indikasi keberadaan hidrokarbon pada data seismik berdasarkan atribut sweetness (Figure 4).

Anomali sweet spots pada data seismik, ditunjukkan oleh lingkaran hitam (Figure 4) yang terletak di rentang waktu antara $750-850 \mathrm{~ms}$ dan posisi antara trace 844-1035. Posisi trace tersebut berdekatan dengan posisi sumur BLJ-1 pada data seismik, yaitu terletak pada posisi trace 985 . Munculnya fenomena sweet spot diindikasikan dengan warna kuning yang merepresentasikan tingginya nilai sweetness pada area tersebut. Warna kuning yang tampak pada atribut ini mengindikasikan tingginya nilai sweetness, sedangkan warna sian mengindikasikan rendahnya nilai sweetness. Tingginya nilai sweetness pada suatu area, mencirikan bahwa area tersebut memiliki nilai amplitudo yang tinggi dan frekuensi yang rendah. Munculnya sweet spots pada rentang waktu 750-850 ms, dapat disebabkan karena adanya kontras velositas antara lapisan batuan yang memiliki velositas tinggi dengan suatu materi yang memiliki velositas rendah (diduga hidrokarbon). Adanya hidrokarbon pada suatu lapisan batuan, akan mengabsorbsi velositas gelombang seismik sehingga menyebabkan terjadinya akumulasi energi yang berakibat pada tingginya amplitudo daerah tersebut (Putri et al., 2016). 


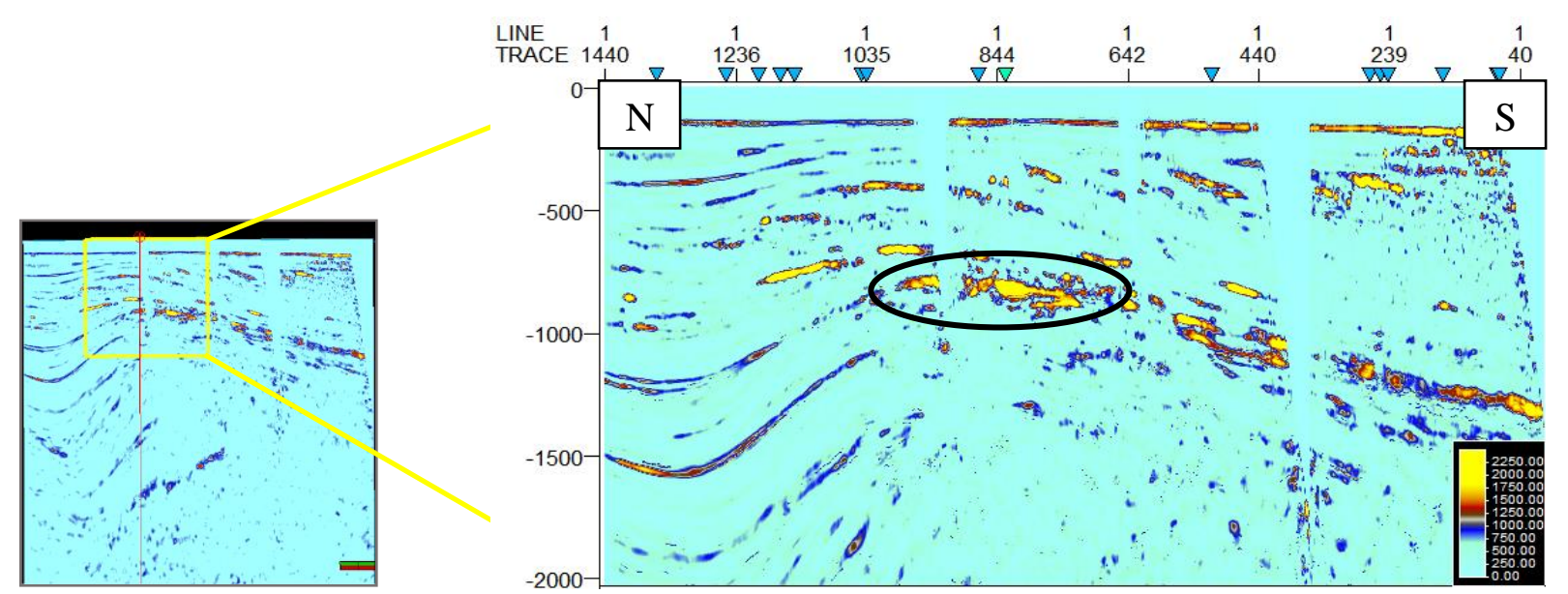

Figure 4. Sweetness attribute from seismic line K1 near BLJ-1 with North-South (N-S) trend. The black circle indicates "sweet spots" anomaly which is suspected to be a reservoir zone.

\subsection{Analisis Data Log}

Data log adalah data bawah permukaan yang sensitif terhadap perubahan lapisan batuan dan data tersebut dapat digunakan untuk mengidentifikasi zona target reservoir. Identifikasi zona target dilakukan dengan menganalisis secara singkat (quicklook) respons data log dalam bentuk kurva tunggal. Log yang digunakan untuk mengidentifikasi zona target adalah log gamma ray (GR), $\log$ resistivity, $\log$ neutron porosity (NPHI), dan log densitas. Hasil analisis data log pada sumur BLJ-1 (Figure 5).

Zona target reservoir sumur BLJ-1 diduga terletak pada kedalaman $680 \mathrm{~m}$ hingga $740 \mathrm{~m}$. Berdasarkan data marker umur batuan, lapisan batuan pada rentang kedalaman tersebut berumur Late Pliocene dan didominasi oleh batuan karbonat berupa batu gamping (limestone). Rentang kedalaman tersebut diyakini sebagai reservoir karena memiliki nilai log NPHI dan log densitas yang rendah sehingga terjadi separasi saat kedua log di-overlay. Pada rentang kedalaman tersebut juga terjadi penurunan nilai log GR yang sangat signifikan pada batas kedalaman sekitar $680 \mathrm{~m}$ yang menandakan adanya perbedaan litologi pada batas kedalaman tersebut. Selain itu, nilai log resistivity juga meningkat. Hal ini menanda- kan terdapatnya suatu material nonkonduktor atau fluida nonkonduktor dalam batuan yang diduga sebagai hidrokarbon. Dugaan adanya hidrokarbon diperkuat dari hasil drill stem test (DST) yang menunjukkan terdapat aliran gas sebesar 11,3-12,6 million cubic feet of gas per day (MMCFGPD) pada kedalaman $673,61 \mathrm{~m}$ hingga $710,18 \mathrm{~m}$ yang masih termasuk dalam rentang kedalaman zona target (Table 1).

Lapisan batuan reservoir atau zona target reservoir dapat diidentifikasi dari separasi log NPHI dan log densitas. Nilai log NPHI dan densitas yang rendah, saat kedua log di-overlay atau dikombinasikan akan membentuk pola crossover dan terjadi separasi pada kedua log tersebut. Menurut Halomoan et al. (2017), separasi yang terjadi karena rendahnya nilai log NPHI dan densitas dapat mengindikasikan keberadaan hidrokarbon. Log GR dapat memisahkan batuan yang bersifat permeabel dan nonpermeabel berdasarkan tingkat radiasi sinar gamma alami yang terkandung dalam lapisan batuan tersebut. Nilai log GR yang rendah menandakan bahwa lapisan batuan tersebut permeabel, sedangkan nilai log GR yang tinggi menandakan bahwa lapisan batuan tersebut bersifat nonpermeabel (Sidiq et al., 2019). Log resistivity mendeterminasi batuan berdasarkan tahanan listrik (resistan- 


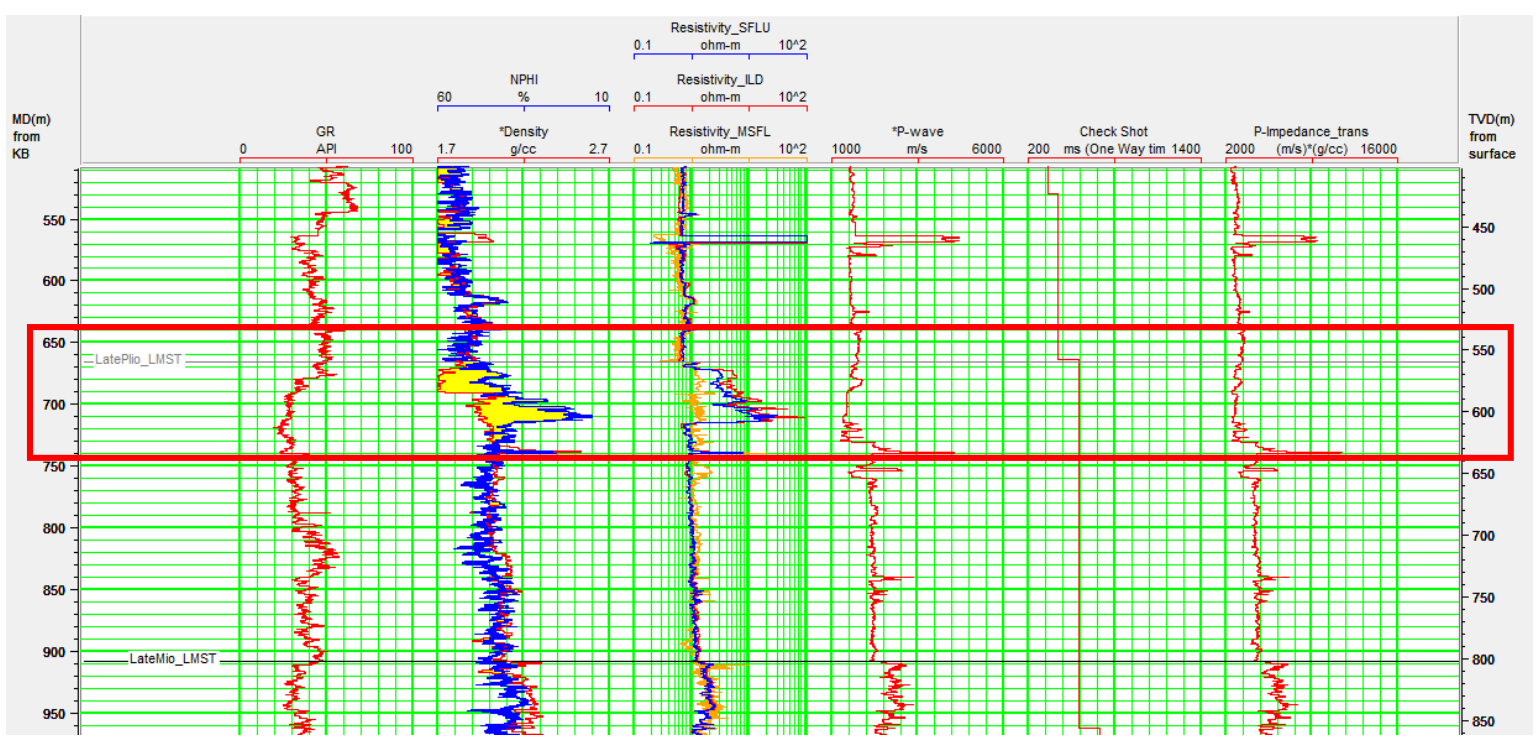

Figure 5. Target zone of BLJ-1 well.

Table 1. DST result for BLJ-1 well.

\begin{tabular}{cll}
\hline DST No. & Depth Interval $(\mathrm{m})$ & \multicolumn{1}{c}{ Result } \\
\hline 1 & $722.38-731.52$ & Dry \\
2 & $701.04-710.18$ & Flow gas 12.6 MMCFGPD \\
3 & $673.61-682.75$ & Flow gas 4.3 MMCFGPD \\
$3 \mathrm{~A}$ & $673.61-682.75$ & Flow gas 11.3 MMCFGPD after acidizing with 18927 L \\
& & 20\% HCl \\
\hline
\end{tabular}

si) dari formasi batuan, serta fluida yang terkandung di dalamnya. Karena sifat hidrokarbon yang nonkonduktif, batuan reservoir yang mengandung hidrokarbon akan memiliki respons resistansi yang besar dibandingkan batuan tanpa hidrokarbon (Ellis \& Singer, 2007).

Hasil analisis berdasarkan penampakan kurva data log dan pengujian sumur (DST), mengindikasikan bahwa di sumur BLJ-1 pada kedalaman 680-740 m merupakan zona prospek hidrokarbon. Oleh karena itu, penelitian ini selanjutnya akan lebih berfokus pada interval kedalaman tersebut.

\subsection{Analisis Well-to-Seismic Tie}

Pengikatan data sumur kepada data seismik (well-to-seismic tie), berguna untuk mengetahui kedalaman aktual zona target reservoir pada data seismik. Wavelet, merupakan komponen penting dalam proses pengikatan dan komponen tersebut berpengaruh terhadap nilai korelasi pengikatan. Adapun wavelet yang digunakan dalam pengikatan sumur BLJ-1, dihasilkan dari proses ekstraksi statistik data seismik. Wavelet hasil ekstraksi statistik data seismik selanjutnya dapat dilihat pada Figure 6 .

Proses ekstraksi wavelet dilakukan pada daerah sekitar zona target, yaitu pada rentang waktu $750-1100 \mathrm{~ms}$. Wavelet yang terbentuk memiliki panjang wavelet (wavelet length) sebesar $180 \mathrm{~ms}$ dengan panjang keruncingan (taper length) sebesar $20 \mathrm{~ms}$ sehingga memiliki karakter puncak yang runcing dan lobus samping (sidelobe) yang kecil (Figure 6a). Selain itu, wavelet yang dihasilkan tersebut memiliki fase nol/zerophase dengan frekuensi dominan sebesar 32 $\mathrm{Hz}$ (Figure 6b). Komponen wavelet tersebut selanjutnya dikonvolusikan dengan reflektivitas untuk menghasilkan seismogram sinte- 
tik yang digunakan pada proses pengikatan data sumur. Pengikatan data sumur dilakukan dengan menyamakan pola seismogram sintetik dengan trace data seismik melalui proses shifting, streching, dan squeezing. Proses shifting dilakukan dengan menggeser posisi waktu, sedangkan proses streching dan squeezing dilakukan dengan menarik dan menghimpit waktu pada seismogram sintetik agar sesuai dengan trace data seismik. Hasil proses pengikatan atau wellto-seismic tie pada sumur BLJ-1 ditunjukkan pada Figure 7.

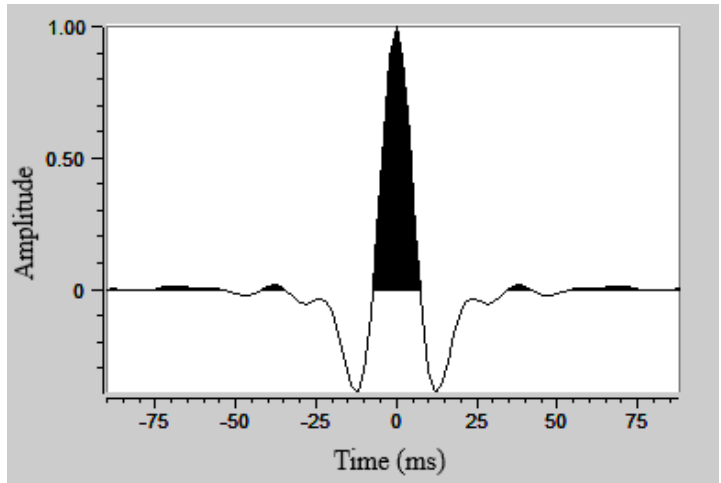

(a)

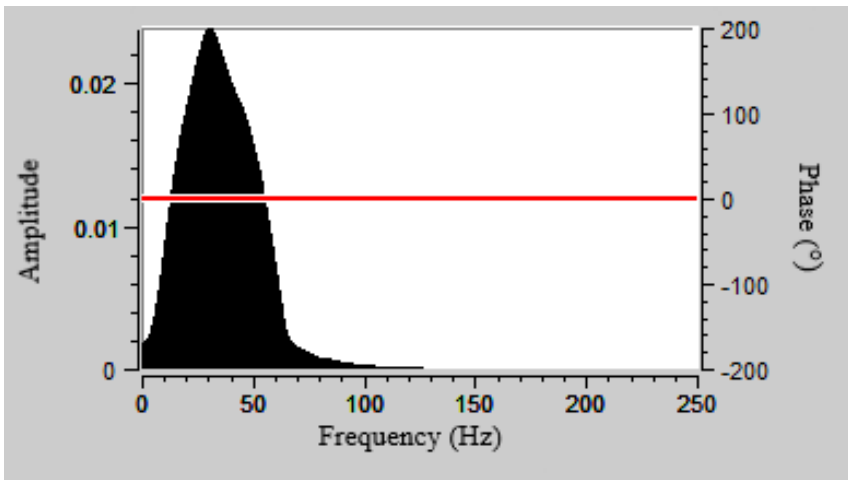

(b)

Figure 6. Wavelet response from seismic data extraction in (a) time and (b) frequency domain.

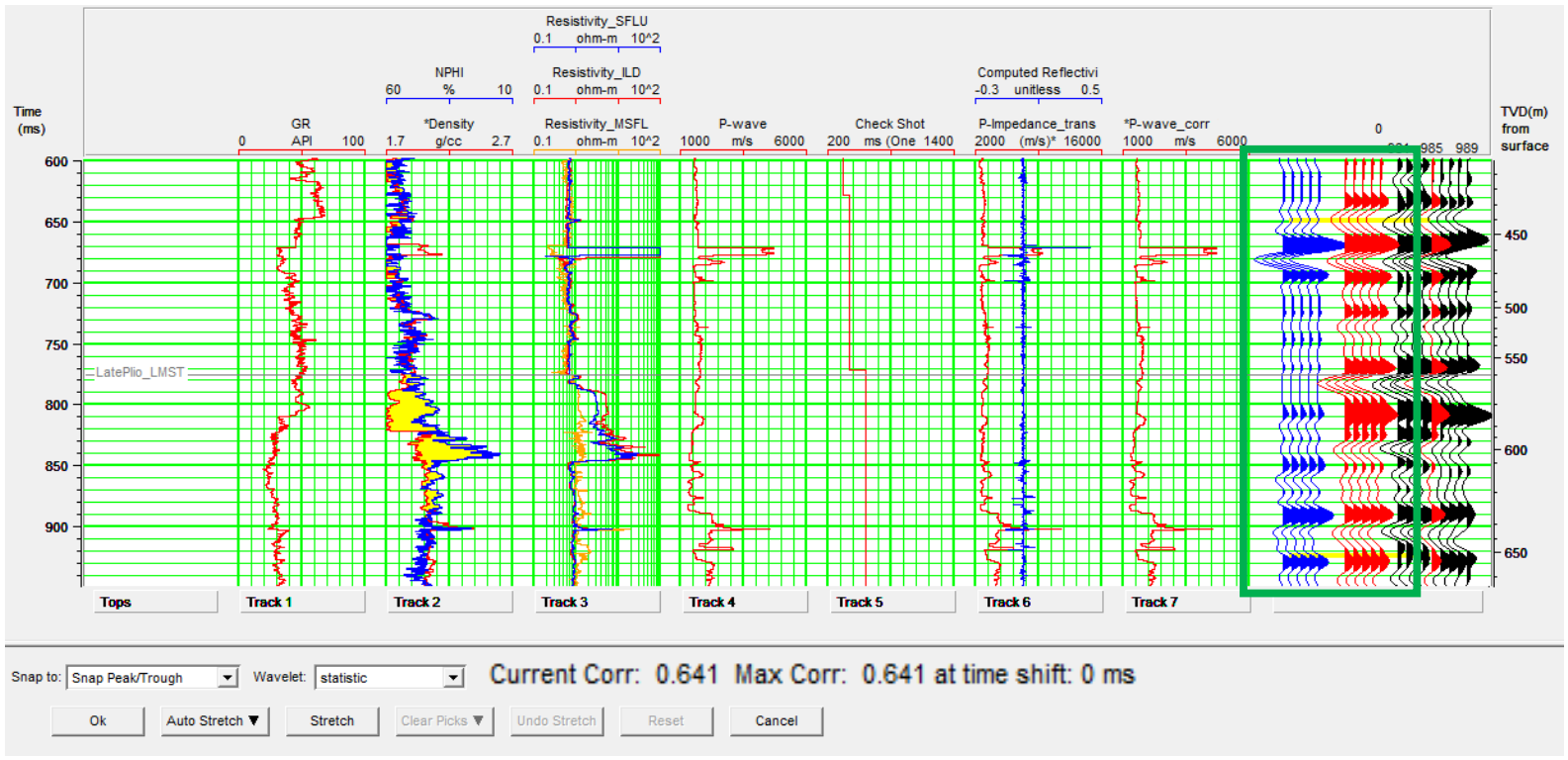

Figure 7. Results of well-to-seismic tie process in BLJ-1 well. The green box is a process of matching synthetic seismogram (blue color) and seismic trace data (red color). 


\subsection{Analisis Model Inisial}

Proses pengikatan data sumur dengan data seismik menghasilkan log baru berupa $\log P$-wave yang sudah terkoreksi. Log tersebut bersama dengan log densitas selanjutnya digunakan untuk membuat log impedansi akustik yang kemudian diekstrapolasi secara lateral menggunakan data seismik sehingga terbentuk model impedansi akustik atau model inisial. Filter lowpass dengan frekuensi high-cut $3 / 10 \mathrm{~Hz}$ digunakan dalam membangun model inisial pada penelitian ini. Model impedansi akustik atau model inisial sumur BLJ-1 dapat dilihat pada Figure 8.

Nilai impedansi akustik yang terbentuk pada model inisial, berkisar antara 2200$7150 \mathrm{~m} / \mathrm{s}^{*} \mathrm{~g} / \mathrm{cm}^{3}$. Besarnya nilai impedansi tersebut, direpresentasikan melalui lapisan warna yang tersusun secara vertikal. Nilai impedansi terendah digambarkan dengan warna hijau tua, sedangkan nilai impedansi tinggi digambarkan dengan warna ungu. Daerah yang berada diantara 2 garis horizon Top dan Bottom adalah daerah target reservoir. Berdasarkan model inisial, daerah tersebut digambarkan dengan warna hijaukuning yang memiliki nilai impedansi akustik sekitar $2200-4000 \mathrm{~m} / \mathrm{s}^{*} \mathrm{~g} / \mathrm{cm}^{3}$.

Filter lowpass dengan frekuensi highcut $3 / 10 \mathrm{~Hz}$ yang digunakan dalam pembuatan model inisial, menghasilkan komponen frekuensi rendah dengan dengan rentang 3-10 Hz. Data seismik memiliki sifat data yang terbatas pada band-nya (band limited) sehingga berakibat pada hilangnya informasi dari frekuensi rendah (0-15 Hz). Informasi dari frekuensi rendah mempunyai peran sangat penting karena sensitivitasnya terhadap sifat batuan yang berpengaruh dalam menentukan fluida, porositas, dan sifat reservoir lainnya (Cooke \& Cant, 2010; Karim et al., 2016).

Penggunaan filter lowpass tersebut pada model inisial bumi, dimaksudkan untuk menyediakan komponen frekuensi rendah yang hilang dari data seismik akibat dari sifat data seismik itu sendiri.

\subsection{Analisis Inversi Seismik}

Proses inversi seismik, diawali dengan terlebih dahulu melakukan analisis pada model inisial yang sebelumnya telah dibangun (analisis pra-inversi). Analisis ini dilakukan untuk mendapatkan parameter inversi yang sesuai karena parameter

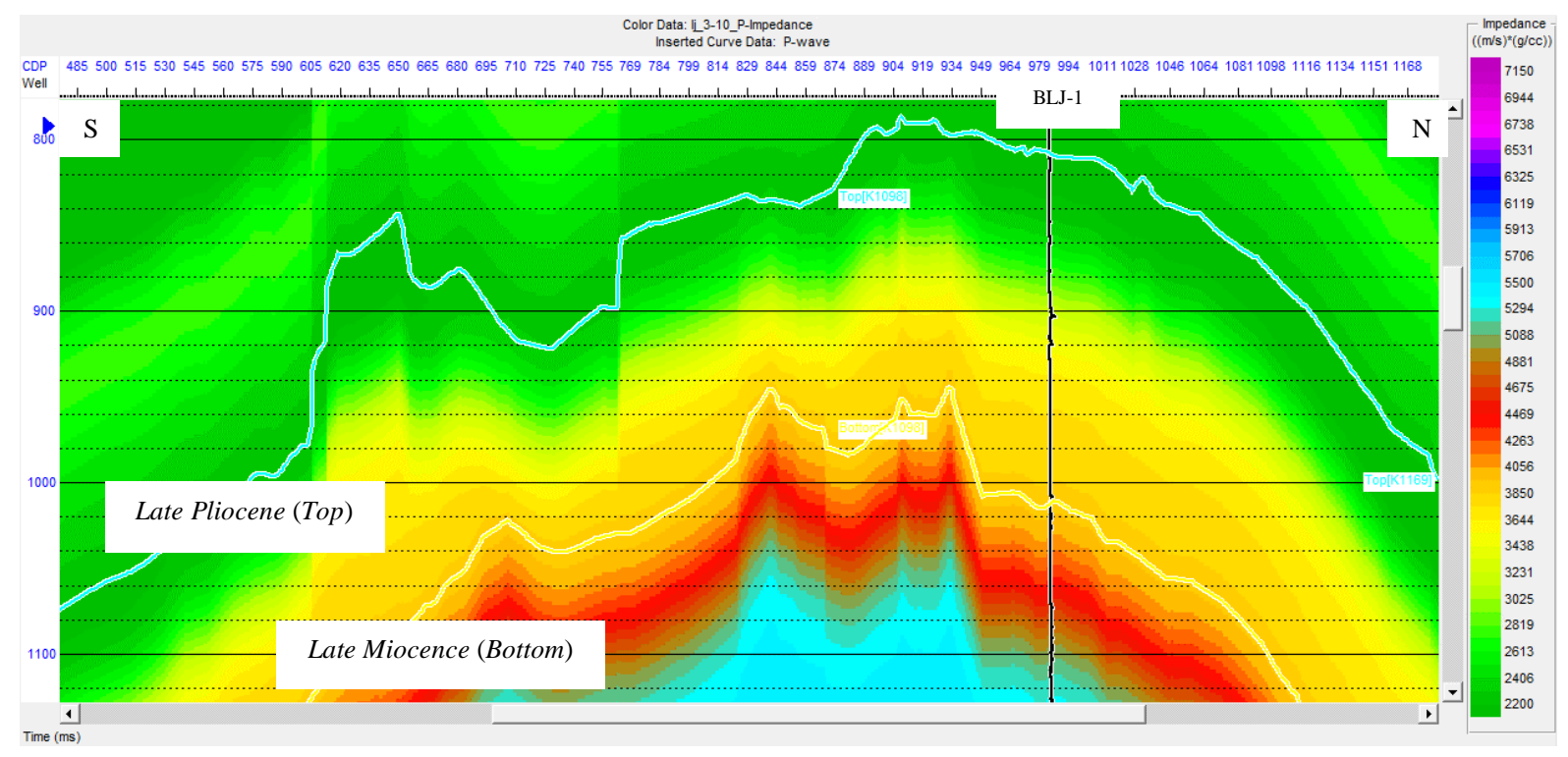

Figure 8. Low frequency acoustic impedance model (initial model) generated from P-wave and density log of BLJ-1 well for inversion process. The cyan and yellow lines are horizon lines that serve as boundaries for the area to be inverted. 


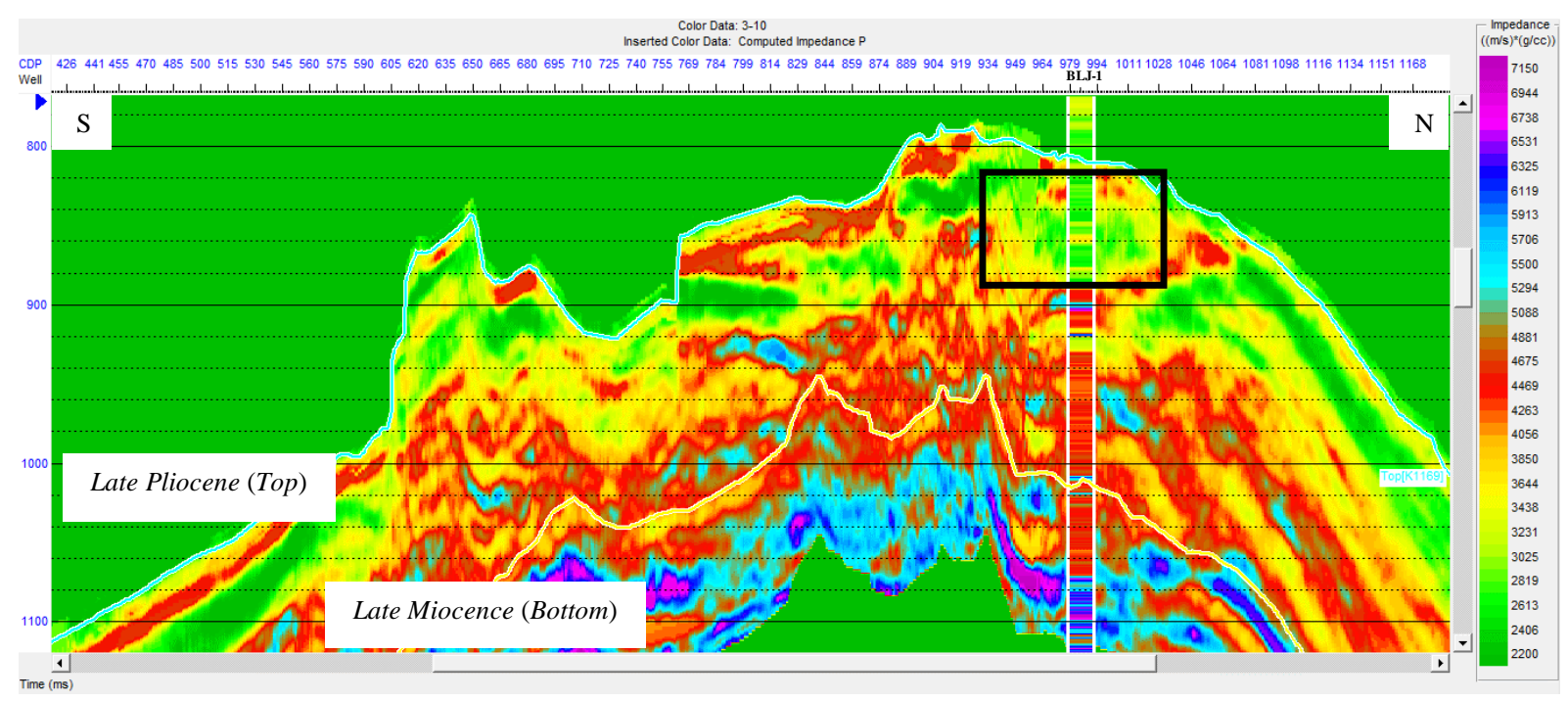

Figure 9. Inverted 2D-seismic section with lateral acoustic impedance variation. The black rectangle shows area with low impedance value around BLJ-1 well.

tersebut dapat berpengaruh kepada kualitas proses inversi dan galat hasil inversi (Rifai et al., 2019). Saat melakukan analisis prainversi, model impedansi akustik hasil inversi dan model impedansi akustik sumur BLJ-1 dibatasi pada jendela waktu (window) 790 ms hingga $1110 \mathrm{~ms}$. Pada tahap ini dilakukan pengaturan pembatasan menggunakan parameter soft constraint dengan nilai 0,21 , average block size $2 \mathrm{~ms}$, prewhitening $1 \%$, dan iterasi sebanyak 7 kali. Pengaturan parameter inversi tersebut menghasilkan galat antara impedansi akustik hasil inversi dengan log impedansi akustik sumur sebesar $631,05 \mathrm{~m} / \mathrm{s}^{*} \mathrm{~g} / \mathrm{cm}^{3}$. Nilai korelasi yang didapat dari pengaturan tersebut juga cukup tinggi, yakni sebesar 0,96 dari nilai korelasi maksimum 1 dengan galat sebesar 0,25 . Rendahnya nilai galat mengindikasikan bahwa model yang terbentuk dapat menggambarkan data seismik asli dengan baik. Hasil proses inversi impedansi akustik berbasis model yang dipadukan dengan log impedansi akustik sumur BLJ-1 dapat dilihat pada Figure 9.

Hasil inversi seismik dapat dilihat dari tersebarnya nilai impedansi akustik secara lateral pada daerah target reservoir batu gamping Late Pliocene yang dibatasi oleh 2 buah horizon, yaitu horizon top dan bottom. Secara lateral, daerah di sekitar sumur BLJ-1 memiliki kisaran nilai impedansi akustik sebesar 2200-5500 $\mathrm{m} / \mathrm{s}^{*} \mathrm{~g} / \mathrm{cm}^{3}$ dengan dominasi nilai impedansi akustik sebesar $3400-4800 \mathrm{~m} / \mathrm{s}^{*} \mathrm{~g} / \mathrm{cm}^{3}$ yang dicirikan warna kuning-merah kecokelatan. Terdapat fenomena bright spot yang ditunjukkan dengan kotak berwarna hitam pada Figure 9. Fenomena bright spot terjadi sebagai respons kontras impedansi akustik pada suatu area dengan area di sekitarnya. Area tersebut memiliki nilai impedansi akustik yang lebih rendah dibandingkan dengan area di sekitarnya, yakni berkisar antara $2200-3400 \mathrm{~m} / \mathrm{s}^{*} \mathrm{~g} / \mathrm{cm}^{3}$ dan dicirikan dengan warna hijau kekuningan. Telah disebutkan di awal, bahwa salah satu komponen yang berpengaruh terhadap nilai impedansi akustik adalah velositas dan rendahnya nilai impedansi akustik pada daerah tersebut diduga karena terdapatnya hidrokarbon berupa gas yang akan me nurunkan velositas akibat dari absorpsi energi.

\section{KESIMPULAN}

Analisis atribut sweetness dapat mengidentifikasi zona reservoir hidrokarbon di Perairan Utara Bali berdasarkan keberadaan anomali sweet spot dengan nilai 
sweetnees yang tinggi pada trace 844-1035 di rentang waktu $750-850 \mathrm{~ms}$. Zona reservoir didominasi batuan karbonat berupa batu gamping (limestone) yang terletak pada kedalaman 680-740 $\mathrm{m}$ dan terdapat adanya aliran fluida berupa gas. Inversi impedansi akustik berbasis model dapat mendeterminasi lapisan batuan reservoir yang diprediksi mengandung gas dengan nilai impedansi rendah, yaitu $2400-3400 \mathrm{~m} / \mathrm{s}^{*} \mathrm{~g} / \mathrm{cm}^{3}$. Inversi impedansi akustik berbasis model menghasilkan nilai korelasi inversi yang tinggi dengan galat yang rendah, sehingga penggunaan metode inversi ini baik dalam proses karakterisasi reservoir hidrokarbon. Penggunaan metode atribut sweetness dan inversi berbasis model, dapat mengidentifikasi dan mampu menggambarkan karakter reservoir hidrokarbon dengan baik.

\section{UCAPAN TERIMA KASIH}

Penulis mengucapkan terima kasih kepada Pusat Penelitian dan Pengembangan Geologi Laut (PPPGL) Bandung atas izin penggunaan data lapangan dan fasilitasnya sehingga penelitian ini dapat terlaksana. Penulis juga mengucapkan terima kasih kepada Bapak Subarsyah S.Si, M.T., Bapak Tumpal B. Nainggolan, S.T, M.T., dan Bapak Shaska R. Zulivandama, S.T, M.T. yang telah membantu dengan saran dan masukannya selama proses pengolahan data.

\section{DAFTAR PUSTAKA}

Brown, A.R. 2001. Understanding seismic attributes. Geophysics, 66(1): 47-48. https://doi.org/10.1190/1.1444919

Chen, Q. \& S. Sidney. 1997. Seismic attribute technology for reservoir forecasting and monitoring. The Leading Edge, 16(5): 445-448. https://doi.org/10.1190/1.1437657

Cooke, D. \& J. Cant. 2010. Model-based seismic inversion: Comparing deterministic and probabilistic approaches. CSEG Recorder, 35(4): 29-39.

https://csegrecorder.com/editions/iss ue/2010-04

Dikman, T., A. Susilo, \& S. Sabbeq. 2015. Korelasi data log sumur dan seismik untuk penyebaran litologi dan porositas reservoir hidrokarbon Formasi Gumai Cekungan Sumatera Selatan. Natural B, 3(2): 166-174. https://doi.org/10.21776/ub.naturalb.2015.003.02.10

Ellis, D.V. \& J.M. Singer. 2007. Basic resistivity and spontaneous potential. Di dalam: Ellis, D.V. \& J. M. Singer (editor). Well logging for earth scientists. Second Edition. Springer. Dordrecht. 41-62 pp. https://doi.org/10.1007/978-1-40204602-5_3

Erryansyah, M., T.B. Nainggolan, \& H.M. Manik. 2020. Acoustic impedance model-based inversion to identify target reservoir: a case study Nias Waters. Di dalam: Manik, H. M. et al. (editor). The 3rd International Conference on Marine Science (ICMS) 2019 "Towards Sustainable Marine Resources and Environment", Bogor, Indonesia, 4 September 2019. https://doi.org/10.1088/17551315/429/1/012033

Febridon, M.N., B.S. Mulyatno, O. Dewanto, \& E. Wijaksono. 2018. Analisis sifat fisis pada reservoar batupasir menggunakan metode seismik inversi impedansi akustik (AI) dan multiatribut pada Lapangan "MNF" Cekungan Bonaparte. J. Geofisika Eksplorasi, 4(2): 3-14. https://doi.org/10.23960/jge.v4i2.11

Halomoan, H.L., B.S. Mulyatno, \& O. Dewanto. 2017. Karakterisasi reservoar dan identifikasi sebaran batuan karbonat menggunakan analisis seismik inversi dan attribute Lapangan "Hatoru” Cekungan Jawa 
Timur utara. J. Geofisika Eksplorasi, 3(3): 57-72.

http://doi.org/10.23960/jge.v3i3.1048

Helland-Hansen, D., I. Magnus, A. Edvardsen, \& E. Hansen. 1997. Seismic inversion for reservoir characterization and well planning in the Snorre Field. The Leading Edge, 16(3): 269-274.

https://doi.org/10.1190/1.1437616

James, A.S., A.M. Ayuk, O.B. Taiwo, O.Oluwatoyin, \& O.M. Taiwo. 2016. A study of seismic hydrocarbon indicators over " $\mathrm{X}$ " Field, Niger Delta. J. Basic and Applied Research International, 16(3): 202-210.

https://ikprress.org/index.php/JOBA $\mathrm{RI} /$ article/view/3898

Karim, S.U., M.S. Islam, M.M. Hossain, \& M.A. Islam. 2016. Seismic reservoir characterization using model based post-stack seismic inversion: In case of Fenchuganj Gas Field, Bangladesh. $J$. of the Japan Petroleum Institute, 59(6): 283-292. https://doi.org/10.1627/jpi.59.283

Koson, S., P. Chenrai, \& M. Choowong. 2014. Seismic attributes and seismic geomorphology. Bulletin of Earth Sciences of Thailand, 6(1): 1-9.

http://www.geo.sc.chula.ac.th/BEST/ volume6/number1/BEST_6_1_001_S anhasuk_Final.pdf

Nanda, N.C. 2016. Seismic data interpretation and evaluation for hydrocarbon exploration and production. Springer. Switzerland. 224 p. https://doi.org/10.1007/978-3319-26491-2

Phillips, T.L., R.A. Noble, \& F.F. Sinartio. 1991. Origin of hydrocarbons, Kangean Block Northern Platform, offshore N.E. Java Sea. Prosiding pertemuan ilmiah tahunan 20 IPA, Jakarta, Indonesia, 8-10 Oktober 1991. 637-662 pp.

Putri, N.A., D.D. Warnana, \& P.H. Wijaya. 2016. Karakterisasi reservoir gas biogenik pada Lapangan "TG" dengan menggunakan atribut inversi IA dan dekomposisi spektral. $J$. Geosaintek, 2(2): 99-106.

http://doi.org/10.12962/j25023659.v2 i2. 1923

Rifai, F.Y., T.B. Nainggolan, \& H.M. Manik. 2019. Reservoir characterization using acoustic impedance inversion and multiattribute analysis in Nias Waters, North Sumatra. Bulletin of the Marine Geology, 34(1): 51-62. http://doi.org/10.32693/bomg.34.1.20 19.637

Russell, B.H. 1988. Introduction to seismic inversion methods. Society of Exploration Geophysicist. Oklahoma. $178 \mathrm{p}$.

Saputra, R., V. Rowi, R. Surjaudaja, \& A. Haris. 2014. Fluid Contact analysis based on fluid replacement modeling on direct hydrocarbon indicator feature in the Mundu Formation, East Java Basin. Prosiding pertemuan ilmiah tahunan 38 IPA, Jakarta, Indonesia, 21-23 Mei 2014. 1333$1344 \mathrm{pp}$.

Satyana, A.H. \& M.E.M. Purwaningsih. 2003. Geochemistry of the East Java Basin: New observation oil grouping, genetic gas types and trends of hydrocarbon habitats. Prosiding pertemuan ilmiah tahunan 29 IPA, Jakarta, Indonesia, 14-16 Oktober 2003. 1-23 pp.

Sidiq, A.P., H.M. Manik, \& T.B. Nainggolan. 2019. Studi komparasi metode migrasi seismik dalam mengkarakterisasi reservoir migas di Blok Kangean, Laut Bali menggunakan inversi impedansi akustik berbasis model. J. Ilmu dan Teknologi Kelautan Tropis, 11(1): 205-2019.

https://doi.org/10.29244/jitkt.v11i1.2 3028 
Simanjuntak, A.S., B.S. Mulyatno, \& M. Sarkowi. 2014. Karakterisasi reservoar hidrokarbon pada Lapangan 'TAB' dengan menggunakan pemodelan inversi impedansi akustik. J. Geofisika Eksplorasi, 2(1): 2-13. https://doi.org/10.23960/jge.v2i01.21 4

Sukandarrumidi. 2017. Geologi minyak dan gas bumi untuk geologist pemula. UGM Press. Yogyakarta. $356 \mathrm{p}$.

Sukmono, S. 2002. Interpretasi seismik refleksi. ITB Press. Bandung. 252 p.

Veeken, P.C.H. \& M. Da Silva. 2004. Seismic inversion methods and some of their constraints. First Break, 22(6): 47-70.

https://doi.org/10.3997/13652397.2004011

Zulivandama S.R., G.M. Hermansyah, \& E. Wicaksono. 2018. Aplikasi metode sweetness dan spectral decomposition untuk identifikasi awal potensi hidrokarbon di Perairan Utara Bali. $J$. Geologi Kelautan, 16(1): 13-23. http://doi.org/10.32693/jgk.16.1.2018 .401

Received : 30 September 2020

Reviewed : 12 November 2020

Accepted : 8 December 2020 